\title{
Usefulness of Nuclear Cardiology Techniques for Silent Ischemia Detection in Diabetics
}

\section{Amalia Peix MD PhD DrSc}

\begin{abstract}
Cardiovascular disease is the main cause of death for diabetics, and in many cases its presence is silent due to cardiac autonomic neuropathy. Thus, early diagnosis of coronary disease is essential, permitting proper risk stratification and appropriate therapy. This paper examines the usefulness of several noninvasive imaging techniques to study cardiovascular diseases in individuals with diabetes mellitus, with emphasis on nuclear cardiology, and proposes a diagnostic algorithm for detection of silent ischemia.
\end{abstract}

Keywords Myocardial perfusion scintigraphy, myocardial perfusion imaging, radionuclide imaging, diabetes mellitus, silent myocardial ischemia, Cuba

\section{INTRODUCTION}

In 2000, global estimates indicated 171 million people had diabetes mellitus (DM), projected to reach 366 million by 2030.[1] As DM evolves, it produces endothelial dysfunction and changes in energy metabolism that lead to atherosclerosis in medium- and large-caliber arteries, creating lesions in coronary, cerebrovascular and peripheral arteries. In diabetics, atherosclerotic plaque tends to develop earlier, evolve more quickly and be more diffuse. All these factors contribute to DM patients having two to four times greater risk of a cardiovascular event than nondiabetics, with cardiovascular disease (CVD) being the main cause of death in these patients.[2] In 2008, WHO reported a combined mortality rate from CVDs and DM of 245 per 100,000 population for adults aged 30 to 70 years.[3]

Cardiac mortality for diabetics with no known coronary disease is the same as that for non-diabetics with a history of acute myocardial infarction, which is why clinical guidelines consider diabetics at high risk for CVD.[2]

Presence of cardiac autonomic dysfunction, common in diabetics,[4] is a factor that influences the frequently silent appearance of myocardial ischemia. Hence the importance of identifying individuals with high risk for cardiovascular events, even prior to symptom onset. DM also affects vascular endothelium, causing endothelial dysfunction.[5] The American Diabetes Association[6] therefore recommends performing stress tests on asymptomatic diabetics who present a minimum of two additional risk factors (such as hypertension, dyslipidemia and smoking). This approach, however, is still controversial.

How can silent ischemia be detected in diabetics? The first step in diagnosing silent ischemia in asymptomatic DM with two or more additional risk factors is a stress test,[7] whether with a treadmill or bicycle ergometer.

Ergometry provides valuable functional results-not only for detecting ischemia, but also for assessing functional capacity, as well as behavior of arterial pressure and arrhythmia on exertion.[7] Its availability and utility make it the first option for patients without diabetic neuropathy who are able to do physical exercise.

In patients with low functional capacity, imaging techniques such as echocardiography or myocardial perfusion scintigraphy (MPS) are more helpful, since they have acceptable sensitivity and specificity, and allow pharmacological stressors (dobutamine in echocardiogram; dipyridamole or dobutamine in MPS) to substitute for physical exercise.[8-12] An alternative for patients able to do physical exercise would be a stress MPS, which combines data from a stress ECG and functional capacity with that from an MPS.

MPS with single-photon emission-computed tomography (SPECT) is a validated nuclear medicine technique for obtaining functional information about the heart by demonstrating myocardial ischemia. If images are synchronized with ECG (gated SPECT or gSPECT), a single study can provide data on myocardial perfusion as well as intraventricular synchronism and ventricular function (left ventricular ejection fraction and systolic wall thickening, which permit assessment of segmental wall-motion abnormalities).[10] gSPECT can be extremely useful in diagnosis and risk stratification in patients with CVD. Nuclear cardiology techniques have been used in Cuba since the 1980s and are currently available free of cost to patients in several tertiary care centers.

Two other imaging techniques, although not used in the same way as echocardiography and MPS to detect ischemia, provide complementary data useful for diagnosis. The first is the coronary calcium score obtained through computed axial tomography (CAT); $[11,12]$ it quantifies calcium in coronary arteries and is therefore an indicator of CVD, although since it provides structural rather than functional information, it cannot detect ischemia. The second method is measurement of endothelial function, which can be assessed in the brachial artery by using ultrasound to measure flow-mediated endothelium-dependent vasodilation, as described by Celermajer.[13] Marcus[14] found that impairment of endothelium-dependent vasodilation in coronary resistance vessels (<450 $\mu \mathrm{m}$ in diameter) may be associated with perfusion abnormalities in diabetics, even in the absence of stenotic lesions in epicardial coronary arteries, suggesting the presence of microvascular CVD. This test is more widely available, since it requires only ultrasound equipment and an echocardiographer trained in the technique.

\section{DIAGNOSTIC APPROACH TO DETECTING SILENT ISCHEMIA IN DIABETICS}

There are several different algorithms for detection of silent ischemia in diabetic patients. The experience of our working group at Cuba's cardiology and endocrinology institutes is reviewed below. All data have been published previously as cited.

As part of multicenter research coordinated with the International Atomic Energy Agency, we studied a group of 59 diabetic patients, 
comparing them with a control group of 42 participants (who were not diabetic but had coronary risk factors) to detect silent ischemia through MPS, coronary calcium score and endothelial function assessment.[15]

We found that $69 \%$ of DM patients with stress-induced ischemia in MPS had impaired endothelium-mediated vasodilation, which can be interpreted as a manifestation of endothelial dysfunction. However, only $43 \%$ of nondiabetic patients with other atherosclerotic risk factors had involvement of endotheliummediated vasodilation.[15]

These results are supported by the findings of Papaioannu,[5] who used ultrasound to measure endothelium-dependent and independent vasodilation in the brachial artery in a subgroup of 75 asymptomatic diabetics in the Detection of Ischemia in Asymptomatic Diabetics (DIAD) study; it was determined that $\geq 8 \%$ endotheliumdependent vasodilation had a negative predictive value of $93 \%$ for CVD.

Perfusion abnormalities have been detected in a relatively high percentage $(25 \%-50 \%)$ of asymptomatic diabetics in different series.[16,17] Two studies have been conducted in Cuba to date using gSPECT: one by Peña,[18,19] which included 220 patients and found ischemia in $29.1 \%$; and the second by Peix,[15] that found $33 \%$ of patients with DM had ischemia versus $16 \%$ of those without $(p=0.04)$. Figure 1 presents an example of a diabetic patient with silent myocardial ischemia diagnosed by gSPECT.

To date, MPS has been used in only two other studies to examine prevalence of ischemia in asymptomatic diabetics: the DIAD study[4] and that of Scholte,[20] which detected ischemia in approximately $20 \%$ and $33 \%$ of cases, respectively, independent of the number of risk factors. However, unlike the Peix study, neither of these used physical exercise as a stressor or had control groups.[15]

Presence of coronary calcium is associated with risk of cardiac events, with 1-99 Agatston units indicating low risk; 100-400, moderate risk; and $>400$, high risk.[21] A prospective study by Anand[11] followed a two-stage strategy: a calcium score was derived for all patients through multislice CAT scan, followed by gSPECT for those who scored $>100$ Agatston units and for a random sample of those with scores of $\leq 100$. Some $32 \%$ of MPS showed perfusion abnormalities corresponding to ischemia. Scintigraphic abnormalities diagnostic of ischemia were present in $23 \%$ of patients with Agatston scores of $>100,48 \%$ of those with scores of $>400$ and $71 \%$ of those with scores of $>1000$. The authors found that the more diffuse the ischemia the worse the clinical evolution; that the calcium score was better than estab- lished risk factors at predicting silent ischemia and cardiac events in persons with DM; and that a coronary calcium score of 0 to 10 Agatston units was associated with normal scintigraphy and excellent prognosis.[11]

In the Peix study, coronary calcium levels in diabetic patients averaged 74 Agatston units compared to 5 in controls $(p=0.01)$.[15] Eight diabetics had calcium scores of $>100$, which in only three cases coincided with presence of perfusion abnormalities on MPS. In two studies in Japan and Israel using CAT scans to compare asymptomatic diabetic with nondiabetic patients,[22,23] prevalence of coronary plaques was $80 \%$ to $93 \%$ in asymptomatic diabetics, and significant coronary stenosis was more prevalent in diabetics than in the control group. Scholte[24] found that $41 \%$ of plaques were not calcified, thus undetectable by calcium scoring, while Raggi[12] found coronary artery calcification in $40 \%$ of diabetics. An appropriate approach for these patients could be the combination of both tests: coronary calcium score and myocardial perfusion scintigraphy, thus providing important complementary data.

The two-stage strategy (calcium score followed by perfusion scintigraphy for patients with scores of $>100$ ) combines both types of data: structural (through coronary calcium) and functional (through MPS-detected ischemia). However, even this should be viewed with caution because, while more useful in cases of calcified epi- 
cardial coronary lesions, this approach could miss noncalcified soft plaques and microvascular angina. Microvascular angina is a diagnosis of exclusion once ischemia is detected in a patient with typical angina and normal epicardial coronary arteries. Missing the presence of noncalcified soft plaques, and so excluding MPS, would be a drawback of this strategy. Presence of DM in addition to peripheral vascular diseases, carotid disease, peripheral neuropathy, autonomic dysfunction, family history of CVD or renal insufficiency confers additional risk and reinforces the need for testing to detect ischemia; we therefore recommend performing MPS in such cases, even if the calcium score is less than 100.

Peña $[18,19]$ found that alterations in lipids, fasting blood sugar, hypertension, smoking and family history of heart disease increased risk of a positive gSPECT two- to five fold. An LDL level of $\geq 100 \mathrm{mg} / \mathrm{dL}$ was the variable conferring greatest estimated risk, while an HDL level of $<44 \mathrm{mg} / \mathrm{dL}$ was the most important standardized variable when several factors were present.

In the Peix series, DM was the only significant risk factor associated with perfusion abnormalities $(p=0.03$ ). However, coronary calcium of $>100$ Agatston units, abnormal endothelium-dependent vasodilation $(<5 \%)$ and a cholesterol/ $\mathrm{HDL}$ index of $>4$ were associated with perfusion abnormalities in asymptomatic diabetics.[15]

Another interesting aspect that can be evaluated through nuclear techniques is cardiac autonomic innervation, which is frequently impaired in individuals with DM; such impairment constitutes an independent marker of poor prognosis, probably due to increased rates of sudden death from malignant ventricular arrhythmia. The most common method is SPECT scintigraphy with metaiodobenzylguanidine, a norepinephrine analogue, labeled with iodine-123 (123l). Patients with DM and cardiac autonomic neuropathy have reduced myocardial metaiodobenzylguanidine uptake, which has been associated with long-term adverse cardiovascular events.[25]

After completion of the DIAD study and publication of its five-year results, $[4,26,27]$ although screening did not have an impact on adverse cardiac events overall, it was useful in classifying patients as high risk (moderate-to-severe abnormalities and ischemia on stress ECG) and low risk (small defects or normal perfusion). Hence it would be preferable to test for ischemia more selectively rather than testing all diabetics.
We suggest that asymptomatic patients who have had DM for at least five years and are able to do physical exercise take an ergometric test every two years to detect silent ischemia. For those with inconclusive ergometry and two risk factors in addition to DM, we suggest including an endothelium-dependent vasodilation test and coronary calcium score prior to performing an imaging stress test (either stress echocardiography or MPS).

In patients who are unable to do physical exercise, an alternative to consider is pharmacological stress with dobutamine or dipyridamole (either echocardiography or MPS). Figure 2 presents an overview of this algorithm proposed for diagnosing silent ischemia in diabetics.

Interestingly, in $79 \%$ of patients in the DIAD study with ischemia on initial MPS, ischemia resolved in the third year.[26] This pattern was associated with intensified treatment using aspirin, statins and angiotensin-converting enzyme inhibitors. However, the authors point out that since the study was not designed as a treatment trial, this association cannot be considered evidence of a causal relation.

Our working group is currently conducting a third-year assessment of the diabetic group studied. To date, we have observed resolution of ischemia in $71 \%$ of cases, also coinciding with intensified medical treatment and more aggressive control of coronary risk factors (Peix A, Cabrera LO, Castillo I, Heres F, Rodríguez L, Padrón K, Valiente J, Llanes R, Mendoza V, Licea M, Gárciga F,
Figure 2: Proposed algorithm for detecting silent ischemia in asymptomatic diabetic patients

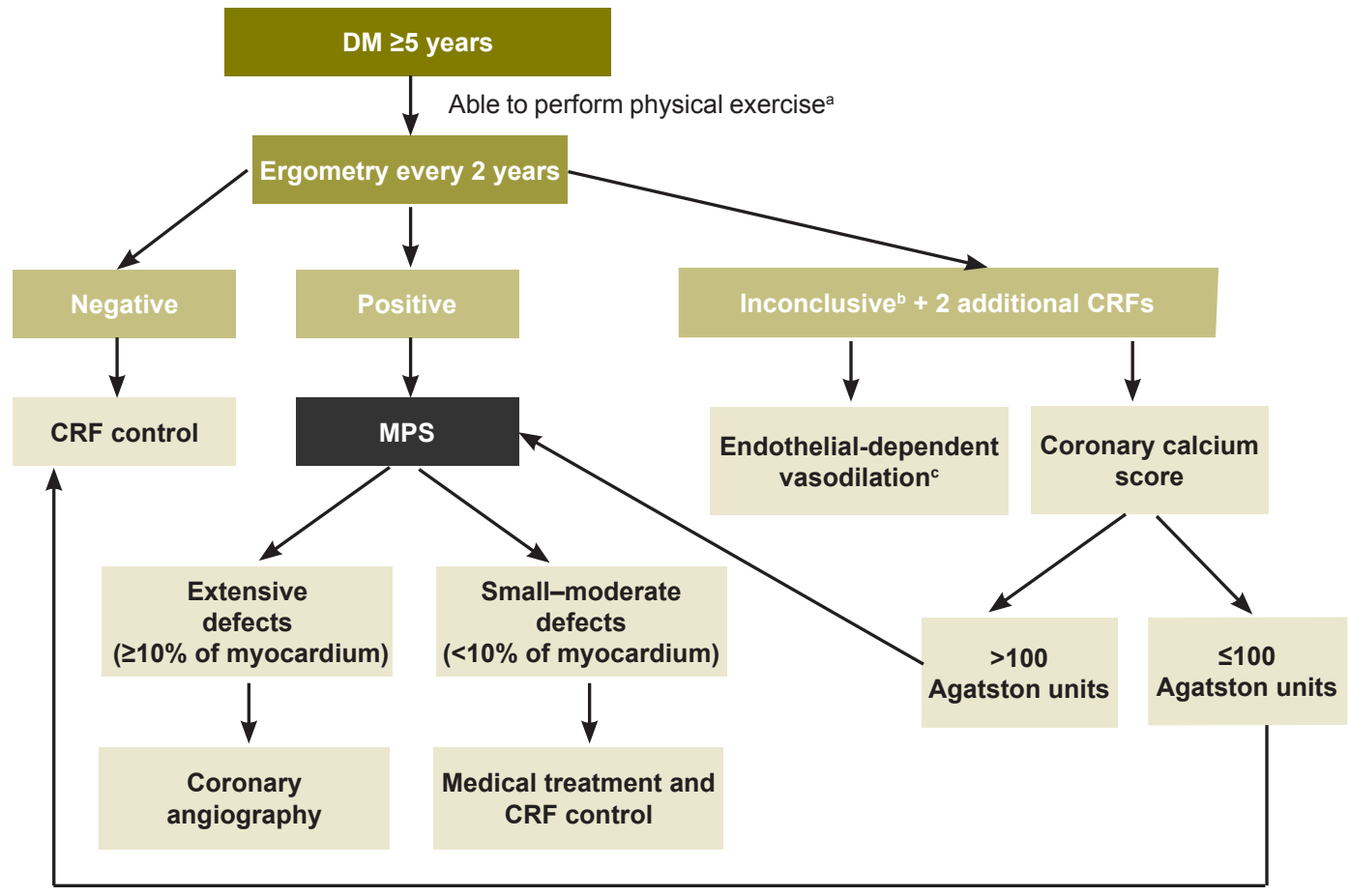

DM: diabetes mellitus CRF: coronary risk factors

MPS: myocardial perfusion scintigraphy

a If patients cannot perform exercise, pharmacological stress can be applied with dobutamine or dipyridamole (with echocardiogram or MPS)

${ }^{b}$ When patient does not reach submaximal heart rate: $85 \%$ of maximum (220 minus age)

${ }^{\mathrm{c}}$ Altered endothelium-dependent vasodilation provides information on endothelial function to better orient treatment 
Dondi M; unpublished data), similar to the DIAD results. This line of inquiry requires more extensive prospective studies, emphasizing the need for early diagnosis of ischemia in these patients through diagnostic techniques available in Cuba and described above. Early detection of ischemia will support customized individual treatment with both medications and appropriate management of behavioral risk factors.

\section{CONCLUSIONS}

Noninvasive imaging techniques have been shown to be extremely useful in diagnostic and prognostic assessment of coronary disease in individuals with DM, but such techniques must always be judiciously applied and in combination with clinical examination, evaluating atherosclerotic risk factors and applying an appropriate diagnostic algorithm. -1 -

\section{REFERENCES}

1. Wild S, Roglic G, Green A, Sicree R, King H. Global prevalence of diabetes. Estimates for the year 2000 and projections for 2030. Diabetes Care. 2004 May;27(5):1047-53.

2. Backer G, Ambrosioni E, Boch-Johnsen K, Brotons $\mathrm{C}$, Cifkova R, Dallongeville J, et al. European guidelines on cardiovascular disease prevention in clinical practice. Third Joint Task Force of European and other Societies on Cardiovascular Disease Prevention in Clinical Practice (consulted by representatives of eight societies and by invited experts). Eur J Cardiovasc Prev Rehabil. 2003;10 Suppl:S1-78.

3. Estadísticas Sanitarias Mundiales [Internet]. Geneva: World Health Organization; 2012 [cited 2012 Aug 5]. 178 p. Available from: www.who.int/ gho/publictions/world_health_statistics/2012/es/ index.html. Spanish.

4. Wackers FG, Young LH, Inzucchi SE, Chyun DA, Davey JA, Barrett EJ, et al. Detection of silent myocardial ischemia in asymptomatic diabetic subjects: the DIAD study. Diabetes Care. 2004 Aug;27(8):1954-61.

5. Papaioannu G, Kasapis C, Seip RL, Grey NJ, Katten D, Wackers FJ, et al. Value of peripheral vascular endothelial function in the detection of relative myocardial ischemia in asymptomatic type 2 diabetic patients who underwent myocardial perfusion imaging. J Nucl Cardiol. 2006 May-Jun;13(3):362-8.

6. American Diabetes Association. Standards of medical care for patients with diabetes mellitus (Position Statement). Diabetes Care. 2003 Mar;26 Suppl 1:S33-50.

7. Gibbons RJ, Balady GJ, Bricker JT, Chaitman BR, Fletcher GF, Froelicher VF, et al. ACC/AHA 2002 guideline update for exercise testing: a report of the American College of Cardiology/ American Heart Association Task Force on Practice Guidelines (Committee to Update the 1997 Exercise Testing Guidelines). Circulation. 2002 Oct 1;106(14):1883-92.

8. Fateh-Moghadam S, Reuter T, Htun P, Plöckinger U, Dietz R, Bocksch W. Stress echocardiography for risk stratification of asymptomatic patients with type 2 diabetes mellitus. Int J Cardiol. 2009 Jan 9;131(2):288-90.

9. Jacqueminet $S$, Barthélémy $O$, Le Feuvre $C$. Screening of silent myocardial ischemia in type 2 diabetic patients: a randomized trial comparing isotopic and echocardiographic stress tests. Diabetes Care. 2010 Jun;33:e79.

10. Beller GA, Heede RC. SPECT imaging for detecting coronary artery disease and determining prognosis by noninvasive assessment of myo- cardial perfusion and myocardial viability. J Cardiovasc TransI Res. 2011 Aug;4(4):416-24.

11. Anand DV, Lim E, Hopkins D, Corder R, Shaw LJ, Sharp P, et al. Risk stratification in uncomplicated type 2 diabetes: Prospective evaluation of the combined use of coronary artery calcium imaging and selective myocardial perfusion scintigraphy. Eur Heart J. 2006 Mar;27(6):713-21.

12. Raggi $P$, Shaw LJ, Berman DS, Callister TQ Prognostic value of coronary calcium screening in subjects with and without diabetes. J Am Coll Cardiol. 2004 May 5;43(9):1663-9.

13. Celermajer D, Sorensen K, Gooch V, Spiegelhalter D, Miller O, Sullivan I. Non-invasive detection of endothelial dysfunction in children and adults at risk of atherosclerosis. Lancet. 1992 Nov;340(8828):1111-5.

14. Marcus ML, Chilian WM, Kanatsuka H, Dellsperger KC, Eastham CL, Lamping KG. Understanding the coronary circulation through studies at the microvascular level. Circulation. $1990 \mathrm{Jul} ; 82(1): 1-7$.

15. Peix A, Cabrera LO, Heres F, Rodríguez L, Valdés $\mathrm{A}$, Valiente $\mathrm{J}$, et al. Interrelationship between myocardial perfusion imaging, coronary calcium score, and endothelial function in asymptomatic diabetes and controls. J Nucl Cardiol. 2011 May;18(3):398-406.

16. Rajagopalan N, Miller TD, Hodge DO, Frye RL, Gibbons RJ. Identifying high-risk asymptomatic diabetic patients who are candidates for screening stress single-photon emission computed tomography imaging. J Am Coll Cardiol. 2005 Jan 4;45(1):43-9.

17. Zellweger MJ, Hachammovitch R, Kang X, Hayes SW, Friedman JD, Germano G, et al. Prognostic relevance of symptoms versus objective evidence of coronary artery disease in diabetic patients. Eur Heart J. 2004 Apr;25(7):543-50.

18. Peña $Y$, Coca M, Batista J, Fernández-Britto J, Quesada R, Peña A. Utilidad de la tomografía computarizada de emisión de fotón único sincronizada con el electrocardiograma para la detección de isquemia miocárdica silente en diabéticos tipo 2. Rev Méd Chile. 2009;137:1023-30. Spanish.

19. Peña Y, Fernández-Britto JE, Bacallao J, de León ML. Lipid levels as predictors of silent myocardial ischemia in a type 2 diabetic population in Havana. MEDICC Rev. 2012 Jan;14(1):18-24.

20. Scholte AJ, Schuijf JD, Kharagjitsingh AV, Dibbets-Schneider P, Stokkel MP, van der Wall EE, et al. Prevalence and predictors of an abnorma stress myocardial perfusion study in asymptomatic patients with type 2 diabetes mellitus. Eur $\mathrm{J}$ Nucl Med Mol Imag. 2009 Apr;36(4):567-75.
21. Greenland $\mathrm{P}$, Bonow $\mathrm{RO}$, Brundage $\mathrm{BH}$, Budof MJ, Eisenberg MJ, Grundy SM, et al. ACCF/ AHA 2007 Clinical expert consensus document on coronary artery calcium scoring by computed tomography in global cardiovascular risk assessment and in evaluation of patients with chest pain. J Am Coll Cardiol. 2007 Jan 23;49(3):378-402.

22. Iwasaki K, Matsumoto T, Aono H, Furukawa $\mathrm{H}$, Samukawa M. Prevalence of subclinical atherosclerosis in asymptomatic diabetic patients by 64-slice computed tomography. Coron Artery Dis. 2008 May;19(3):195-201.

23. Zeina A, Odeh M, Rosenschein U, Zaid G, Barmeir E. Coronary artery disease among asymptomatic diabetic and nondiabetic patients undergoing coronary computed tomography angiography. Coron Artery Dis. 2008 Feb;19(1):37-41.

24. Scholte A, Schuijf J, Kharagjitsingh A, Jukema J, Pundziute G, van der Wall E, et al. Prevalence of coronary artery disease and plaque morphology assessed by multislice computed tomography coronary angiography and calcium scoring in asymptomatic patients with type 2 diabetes. Heart. 2008;94(3):290-5.

25. Nagamachi S, Fujita S, Nishii R, Futami S, Tamura S, Mizuta M, et al. Prognostic value of cardiac I-123 metaiodobenzylguanidine imaging in patients with non-insulin-dependent diabetes mellitus. J Nucl Cardiol. 2006 JanFeb;13(1):34-42.

26. Wackers FJ, Chyun DA, Young LH, Heller GV, Iskandrian AE, Davey JA, et al. Resolution of asymptomatic myocardial ischemia in patients with type 2 diabetes in the Detection of Ischemia in Asymptomatic Diabetics (DIAD) Study. Diabetes Care. 2007 Nov;30(11):2892-8.

27. Young LH, Wackers FJ, Chyun DA, Davey JA, Barrett EJ, Taillefer R, et al. Cardiac outcomes after screening for asymptomatic coronary artery disease in patients with type 2 diabetes. The DIAD Study: a randomized controlled trial. JAMA 2009 Apr 15;301(15):1547-55.

\section{THE AUTHOR}

Amalia Peix (peix@infomed.sld.cu), cardiologist. Full professor and senior researcher, Cardiology and Cardiovascular Surgery Institute, Havana, Cuba.

Submitted: May 30, 2012

Approved for publication: December 27, 2012 Disclosures: None 